\title{
SUSTAINABLE MOBILITY IN THE CITY OF BRATISLAVA - TRAM PRIORITY
}

United Nations Development Programme (UNDP), acting as an implementing agency of the Global Environment Facility (GEF) implemented the project "Sustainable Mobility in the City of Bratislava". One component of the project deals with a higher level of priority to Bratislava's trams.

Driving time information from the ITCS of Bratislava public transport operator was evaluated with Hamburg-Consults software "planfahrt" in order to find obstacles responsible for slowing down tram operation. Thereafter measures based on best practice solutions were introduced for a fast and reliable tram operation: "The tram stops at stations only".

Integral part was the simulation of public transport priority at three signalized intersections using transport modelling software "ptv VISSIM". The results prove the effectiveness of the priority. Public transport waiting times are reduced; the reliability of public transport operations improves.

Keywords: Public transport, tram, transport planning, ITCS, driving times, public transport priority.

\section{Introduction}

The transport sector is the third largest polluting sector in the Slovak Republic with respect to the emissions of greenhouse gases, after Energy and Manufacturing. CO2 emissions from transport represented $14.5 \%$ of the total national GHG emissions in the Slovak Republic in 2010 [1]. The United Nations Development Programme (UNDP), acting as an implementing agency of the Global Environment Facility (GEF), is implementing the project "Sustainable Mobility in the City of Bratislava" financed by GEF within the umbrella of its Operational Program 11 and Strategic Program 5 Promoting Sustainable Innovative Systems for Urban Transport [2].

This part of the project deals with a higher level of priority to Bratislava's trams at signalized intersection in order to increase the service speeds. Additionally to the project title the focus was extended to all components of a modern tram system.

Exemplarily two out of four tram branches were surveyed in order to find obstacles responsible for slowing down tram operation. Both Racianska and Vajnorska branches have a widely separated alignment from the individual transport. Therefore, priority measures can be realised comparatively easily. Multiple tram lines serve each corridor with headways up to 4 minutes together [3].

The project was realized between June 2011 and February 2012. First, it was evaluated whether the selected tram corridors comply with design principles and system parameters of modern tram operations. By detailed analyses of ITCS (Intermodal Transport Control System) data main bottlenecks were located. Afterwards in-depth analyses of three intersections were carried out. The effectiveness of priority measures was checked by a micro-simulation model.

Stakeholders in this project were:

- UNDP as the implementing agency represented by UNDP Bratislava Regional Centre,

- Energy Centre Bratislava as the central project manager,

- Hamburg-Consult (HC) providing international expertise together with VerkehrsConsult Dresden-Berlin responsible for the modelling, and

- DIC Bratislava as a local counterpart.

At all stages, the local municipality (namely the Main Transport Engineer of Bratislava) and the local public transport operator Dopravny Podnik Bratislava (DPB) participated and supported the project.

\section{Survey of current situation}

Besides a comprehensive field survey, main bottlenecks and shortcomings should be assessed in a quantitative way. Therefore, the realised driving times of Bratislava trams were evaluated. Bratislava public transport company DPB provided us with performing data from their operation control system. Nearly 20,000 trips representing the traffic situation in March 2011 were transferred to Hamburg-Consult's software "planfahrt". This software used by more than 100 public transport operators and authorities in Europe is designed for analysing data from Automatic Passenger Counting systems as well as driving time surveys [4].

\section{* Jan Fischer}

Hamburg-Consult GmbH, Transport Planning and Public Transport Operations, Hamburg, Germany, E-mail: j.fischer@hamburg-consult.de 
Driving times on Racianska corridor

\begin{tabular}{|c|c|c|c|c|c|c|}
\hline Station & $\begin{array}{l}\text { Distance } \\
\text { (m) }\end{array}$ & $\begin{array}{c}\text { Theoretical } \\
\text { (shortest) driving } \\
\text { time (s) }\end{array}$ & $\begin{array}{l}\text { Realised average } \\
\text { driving time (s) }\end{array}$ & $\begin{array}{l}\text { Deviation } \\
\quad(s)\end{array}$ & Deviation (\%) & $\begin{array}{l}\text { Average dwell } \\
\text { time (s) }\end{array}$ \\
\hline \multicolumn{7}{|l|}{ Racianske myto } \\
\hline Ursinyho & 502 & 49 & 69 & 21 & $42 \%$ & 14 \\
\hline Pionierska & 836 & 73 & 139 & 67 & $91 \%$ & 15 \\
\hline Riazanska & 552 & 52 & 84 & 32 & $61 \%$ & 16 \\
\hline Mlada garda & 396 & 41 & 63 & 21 & $52 \%$ & 16 \\
\hline Nam. Biely kriz & 548 & 52 & 77 & 25 & $48 \%$ & 13 \\
\hline ZST Vinohrady & 456 & 45 & 113 & 68 & $150 \%$ & 17 \\
\hline Vozovna Krasnany & 349 & 38 & 81 & 43 & $114 \%$ & 13 \\
\hline Novy zahon & 347 & 38 & 51 & 14 & $36 \%$ & 11 \\
\hline Pekna cesta & 639 & 59 & 91 & 32 & $54 \%$ & 15 \\
\hline Cernockeho & 529 & 51 & 67 & 17 & $33 \%$ & 13 \\
\hline Heckova & 375 & 40 & 61 & 22 & $54 \%$ & 17 \\
\hline Hybesova & 567 & 53 & 80 & 26 & $50 \%$ & 13 \\
\hline Detvianska & 516 & 50 & 77 & 27 & $55 \%$ & 16 \\
\hline Zahumenice & 404 & 42 & 95 & 54 & $128 \%$ & 13 \\
\hline Pri vinohradoch & 530 & 51 & 77 & 26 & $52 \%$ & 10 \\
\hline Komisarky & 164 & 24 & 28 & 4 & $15 \%$ & \\
\hline Total & 7.710 & 757 & 1.254 & 497 & $66 \%$ & 213 \\
\hline
\end{tabular}

Main bottlenecks are located at following sections

- Nam. Biely kriz - ZST Vinohrady: 68 s / 150\%

- Ursinyho - Pionierska: 67 s / $91 \%$

- Detvianska - Zahumenice: 54 s / $128 \%$

The performance data indicate e.g. for Racianska branch an average journey time of 24.5 minutes. As the timetable states a driving time of 20 minutes, an average delay of 4.5 minutes shows the unreliability of tram operations [5]. Additionally, a theoretical minimum driving time consisting of the vehicle performance and station spacing distance was calculated with 12.6 minutes $(+3.5$ minutes total dwell time at the stations). The gap between the theoretical and realised driving times represents the potential for tram priority. A total utilization of this potential would increase the attractiveness of the tram system and would additionally save 3 vehicles under the conditions of the current timetable. Table 1 shows the results for Racianska branch.

The combination of the driving time evaluation with the field survey demonstrates the bottlenecks in a very obvious way and allows for creating applicable improvements. The following Fig. 1 shows an extract of Racianska branch.

After the analyses of current situation, measures were introduced in order to realize the mentioned potential and to ensure the fast and reliable tram operation: "The tram stops at stations only". All recommendations are based on best practice solutions from the state of the art tram systems consisting of following components:

- Alignment separated from other means of transport,

- Alignment with low level of constraints because of track conditions, curve radii or switches,
- Attractive station design with a focus on safe access and waiting areas,

- Attractive public transport transfer hubs,

- Priority at unsignalized intersections,

- Priority at pedestrian crossings, and

- Priority at signalized intersections.

Outside the Central Business District, Bratislava trams operate almost exclusively on separated alignments but multiple constraints causing severe speed limits can be found. The constraints result from an alignment with tight curve radii, outdated technology of point locks and insufficient maintenance of the track superstructure. Examples are shown in Fig. 2.

The station design has a high importance for the passengers. Stations are the first and last contact points within the public transport system. Therefore, a high amenity embodied in proper waiting areas, barrier-free elevated platforms and easy-accessible entrances at both ends of the platform is crucial for attractiveness of the whole system. Easy-accessible stops with clear passenger routing provide a higher level of safety as well (see Fig. 3). This ensures a fluent and fast operation with minimized interferences.

At unsignalized intersections and pedestrian crossings trams should have the right of way similar to railway crossings. This can be realised by red-dark signals based on train detection as shown in Fig. 4. Individual traffic is only affected if a tram is arriving, 


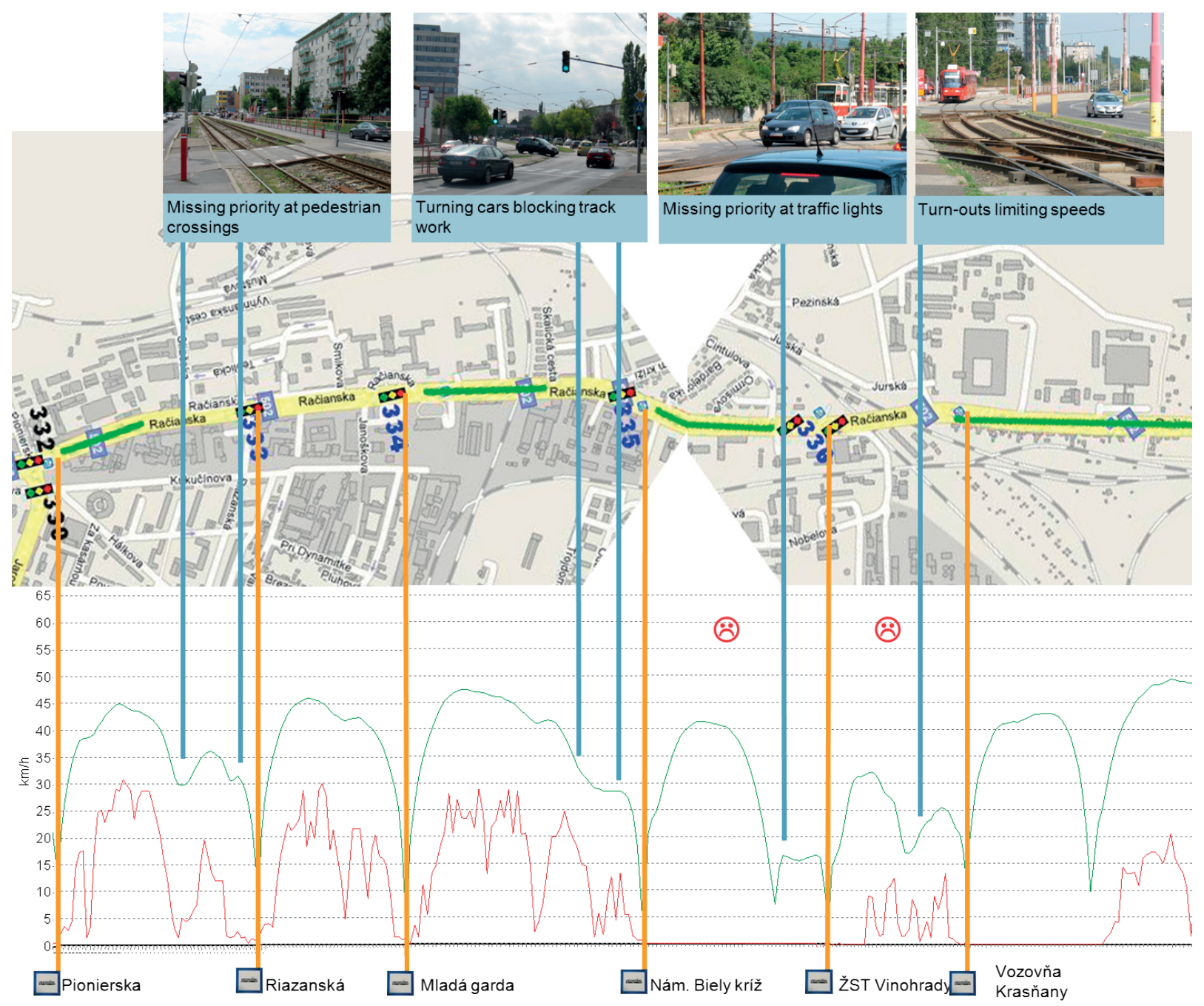

Fig. 1 Realised driving times on Racianska corridor and reasons for interferences and delays
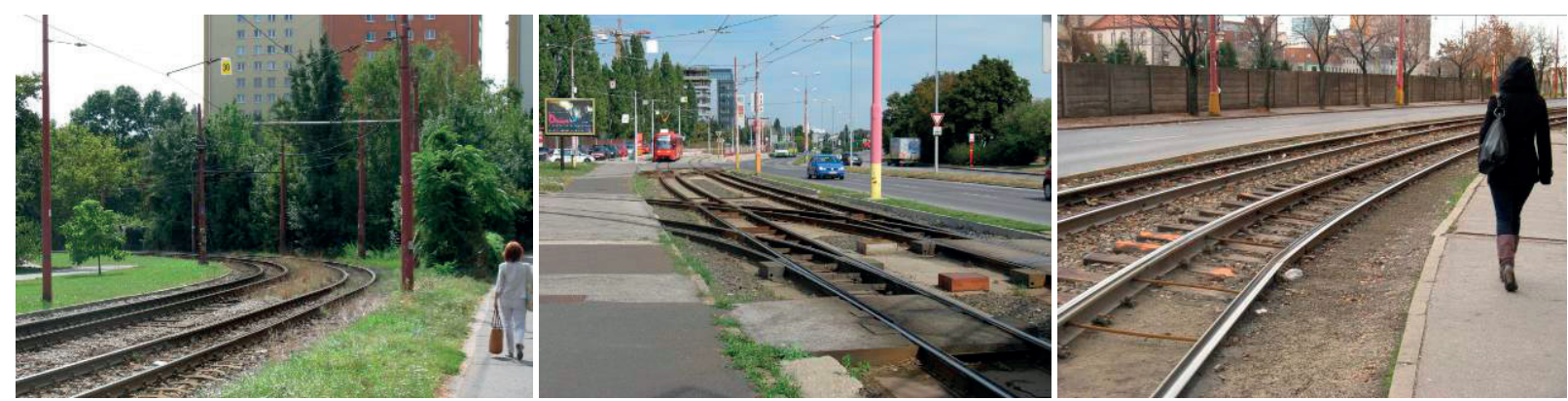

Fig. 2 Speed limitations on Racianska corridor caused by track alignment, switches and insufficient maintenance 

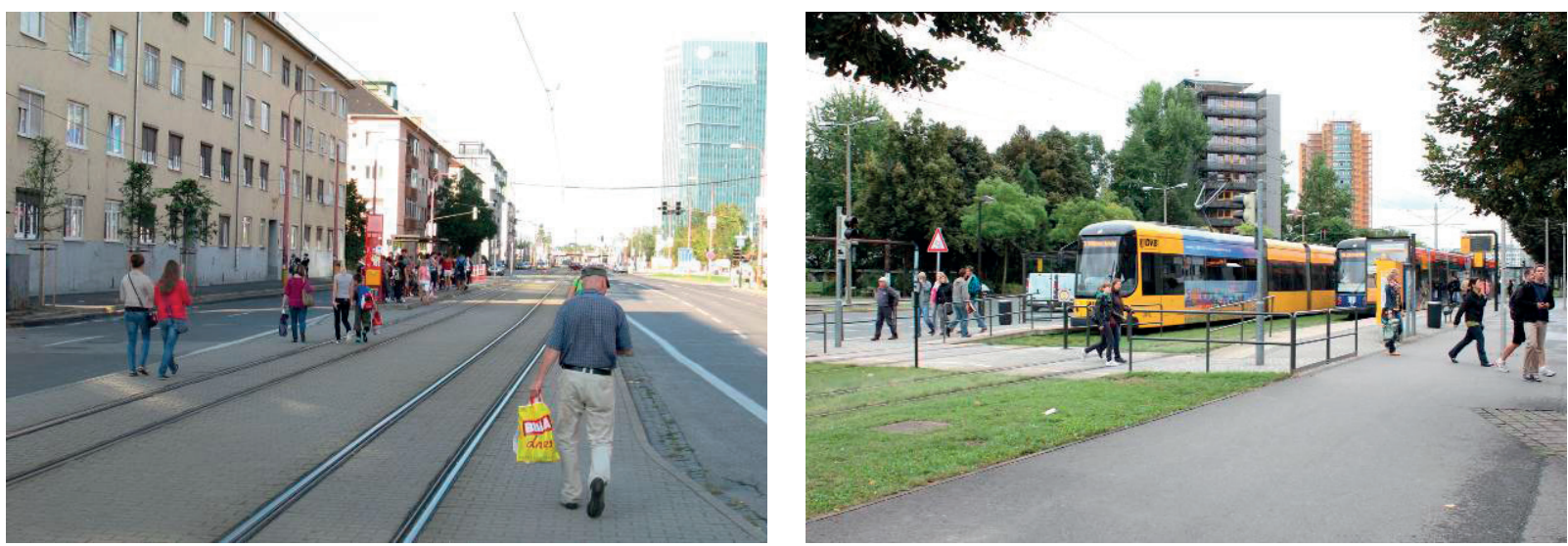

Fig. 3 Station in Bratislava without any passenger guiding system and insufficient waiting capacity, best practice station design in Dresden/Germany
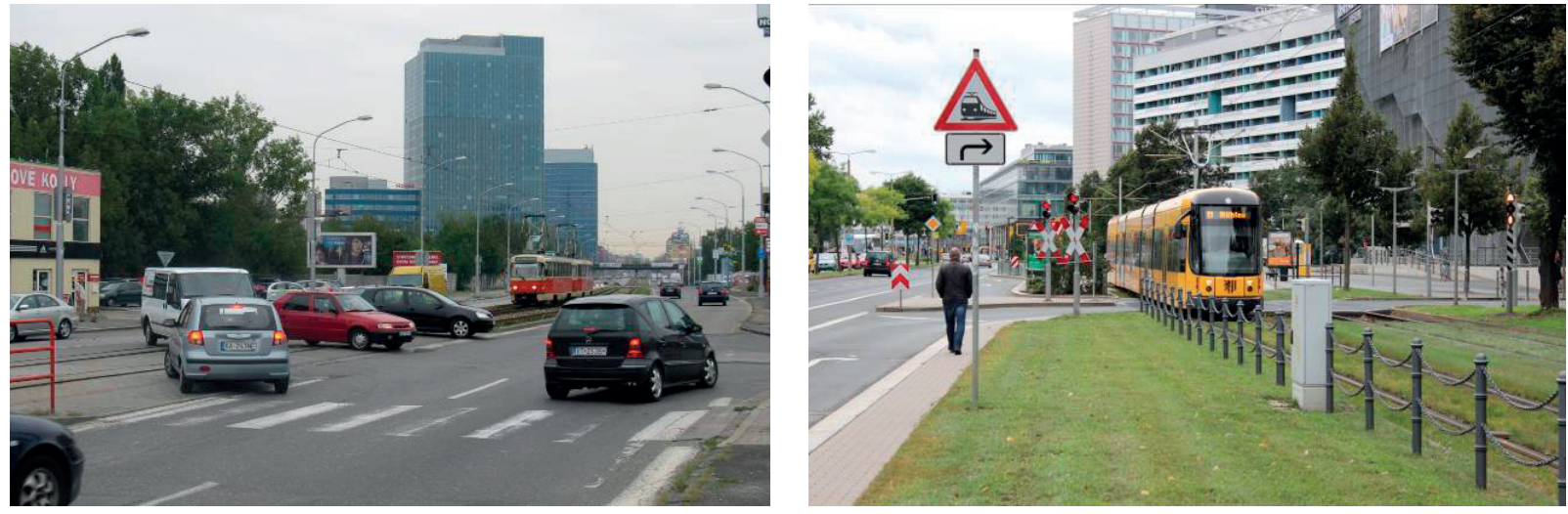

Fig. 4 Unsignalized intersection on Vajnorska branch and "railway crossing" in Dresden/Germany

\section{Priority at signalized intersections}

The priority at signalized intersections is one of the most important measurements for a modern and reliable public transport. Every public transport vehicle needs only $5 \mathrm{sec}$ green period but in the right time. Precise interventions lead to minor interferences for individual transport. A well done priority of public transport is useful for public transport users and has only low impact on other transport modes. Therefore, a precise detection with up to 5 detection points transmitting information of line number and corresponding routing is essential [6].
Integral part of the project was the simulation of public transport priority at three signalized intersections using transport modelling software "ptv VISSIM". Besides trams, buses were considered as well. This can be realised by TETRA radio communication between public transport vehicles and the priority equipment on-site instead of fixed way-side detectors. Two out of three intersections are relatively simple junctions with a high degree of freedom. The third one (Racianska / Jarosova) is more complicated as the traffic light system is coupled with another intersection and a railway crossing.

Average waiting times public transport at intersection Vajnorska / Bojnicka

Table 2

\begin{tabular}{|c|c|c|c|}
\hline Access from & Lines & Current Average Waiting Time (s) & $\begin{array}{c}\text { Average Waiting Time (s) with } \\
\text { Priority }\end{array}$ \\
\hline East & Tram 2 and 4 & 19 & 0 \\
\hline South & Bus 65 & 16 & 4 \\
\hline West & Tram 2 and 4 & 24 & 1 \\
\hline West & Bus 57 & 43 & 4 \\
\hline North & Bus 65 & 11 & 3 \\
\hline
\end{tabular}




\begin{tabular}{|l|c|c|c|}
\hline Access from & Direction & Current Average Waiting Time (s) & Average Waiting Time (s) with Priority \\
\hline East & Right & 1 & 0 \\
& Straight & 38 & 34 \\
& Left & 44 & 39 \\
\hline South & Right & 5 & 12 \\
& Straight & 32 & 48 \\
& Left & 39 & 50 \\
\hline West & Right & 51 & 39 \\
& Straight & 20 & 21 \\
& Left & 15 & 15 \\
\hline \multirow{2}{*}{ North } & Right & 2 & 2 \\
& Straight & 28 & 34 \\
& Left & 41 & 48 \\
\hline
\end{tabular}

The results prove the effectiveness of the priority at intersections with a high level of freedom. Table 2 shows the results of the optimisation at the intersection Vajnorska / Bojnicka for peak hour traffic conditions.

Not only public transport waiting times are reduced but also the range of waiting times. This is crucial for an improved reliability of public transport operations. The results show additionally that a sophisticated traffic light control does not have negative impact on individual transport or the overall capacity of the intersections. Table 3 shows the average waiting time for individual transport at the intersection Vajnorska / Bojnicka for peak hour traffic conditions.

The results of the sample intersections can be easily adapted to other intersections in Bratislava and elsewhere.

\section{Conclusions}

Following key pieces of advice can be extracted from this study:

- Introduction of a priority program at intersections is highly recommended. The technical solution should be identical for tram and buses. The implementation strategy should start at smaller intersections which usually have more degrees of freedom. This ensures reasonable results with comparatively low investment costs.

- Reconstruction of track sections with poor conditions is necessary. Bratislava public transport company has to be provided with sufficient funding in order to maintain the infrastructure regularly before speed reductions appear.

- Introduction of tram priority at pedestrian crossings is highly recommended.

Reduction of unsignalized intersections and crossings: Remaining intersections should be equipped with traffic lights ensuring a strong priority for trams - similar like trains on railway crossings.

- Reconstruction of stations in order to provide safe and comfortable waiting and access areas. An implementation strategy for the construction of interchanging hubs should be accompanied by a re-design of the public transport network. The parallel alignment of trams and buses - both local and regional - should be reduced to a minimum.

- Updating the track alignment on essential sections: Changing curve radii or the location of switches and stations in order to increase the allowed speed.

Within the framework of this UNDP GEF project a sample implementation of tram priority will be realised at two street crossings, namely Racianska / Pekna cesta and Vajnorska / Bojnicka by the end of 2013. The project pushes the idea of public transport priority in Bratislava successfully. It is recommended to extend the project's approach to main bus and trolleybus lines as well. A transfer to other Slovak and European cities can be realised easily.

\section{References}

[1] European Environment Agency: Greenhouse Gas Emission Trends and Projections in Europe 2012, EEA-Report, No. 6/2012, Copenhagen

[2] Global Environment Facility: Detail of GEF Project \#3433, http://www.thegef.org/ gef/project_detail?projID=3433, last visit: 24/04/2013

[3] Dopravny Podnik Bratislava a.s. (Ed.): Internal Timetables for Tramlines 1, 2, 3, 4, 5, 7, 11, 2011, Bratislava

[4] Hamburg-Consult: Planung und EDV im offentlichen Personennahverkehr, http://www.hamburg-consult.de/leistungen/planung-edvim-oeffentlichen-personennahverkehr/\#edvc, last visit: 15/06/2013

[5] Dopravny Podnik Bratislava a.s.: Bratislava Trams Driving Times, 2011, Bratislava

[6] SMITH, H. R.; HEMILY, B., IVANOVIC, M.; FLEMING, G.: Transit Signal Priority: A Planning and Implementation Handbook, Washington, 2005. 